\title{
The Adsorption and Regeneration of Natural Pumice as Low- Cost Adsorbent for Nitrate Removal From Water
}

\author{
Denny Helard ${ }^{1}, *$ Shinta Indah ${ }^{1}$, Chintia Maya Sari ${ }^{1}$, Hestia Mariesta $^{1}$ \\ ${ }^{1}$ Department of Environmental Engineering, Faculty of Engineering, Universitas Andalas
}

* Corresponding Author: dennyhelard@eng.unand.ac.id

Received: 29 Apr 2018. Revised: 25 May 2018, Accepted: 29 May 2018, Published: 1 June 2018

DOI: $10.24273 /$ jgeet.2018.3.2.1545

\begin{abstract}
The potential of adsorption and regeneration of Indonesian natural pumice to remove nitrate from aqueous solution was studied in multiple adsorption-desorption cycles. Batch experiments were performed to examine the effect of various experimental parameters on the removal of nitrate. The optimum condition of nitrate removal by natural pumice were obtained at $3 \mathrm{of} \mathrm{pH}$ solution, $0.3 \mathrm{~g} / \mathrm{L}$ of adsorbent dose, $30 \mathrm{~min}$ of contact time, $<63 \mu \mathrm{m}$ of particle size, and $90 \mathrm{mg} / \mathrm{L}$ of nitrate concentration with $54.79 \%$ of removal efficiency and $164.37 \mathrm{mg} / \mathrm{g}$ of nitrate uptake. The experimental data obtained were fitted with the Freundlich adsorption isotherm within the concentration range studied. Although complete desorption were not achieved, the result confirmed that $\mathrm{HCl}$ can be used as desorbing and recovery agent, which be desorbed 10-13\%of nitrate ion. The used natural pumice also could be regenerated and reused up to three successive adsorption-desorption cycles. Overall results revealed that the ability of natural pumice to adsorb nitrate will create more interest to develop a new adsorbent from local mineral for pollutant removal from water.
\end{abstract}

Keywords: Adsorption, Natural Pumice, Nitrate, Regeneration

\section{Introduction}

Nitrate contamination in ground and surface water has become an increasing and severe environmental problem due to its harmful effect. The most common sources of nitrate in water resources are fertilizers, septic tank effluents, biodegradation of nitro-organic compounds, discharge of raw wastewater, production of explosives, and pharmaceuticals. Due to its high water solubility, nitrate is possibly the most widespread groundwater contaminant in the world, imposing a serious threat to drinking water supplies and promoting eutrophication (Bhatnagar \& Sillanpa, 2011; Liao, 2003). High concentrations of nitrate in drinking water cause health problems, such as cyanosis among children and cancer due to formation of nitrosamine. Therefore, World Health Organization (WHO) and the US Environmental Protection Agency (EPA) set the maximum acceptable contaminant level for nitrate for drinking water are $50 \mathrm{mg} / \mathrm{L}$ and $45 \mathrm{mg} / \mathrm{L}$ of nitrate respectively (Ward et al., 2005).

Numerous techniques for the removal of nitrate from water samples have been reported. These include biological de-nitrification (Schipper et al., 2001), chemical reduction (Hu et al., 2001), reverse osmosis, electrodialysis (Pinter et al., 2006), and ion exchange (Baes et al., 2002). Adsorption is another effective technique for nitrate removal and has been shown to be an economical and effective alternative for removing ions from water because of its interesting features, including low costs, easy design, and operation. Different adsorbents have been used for nitrate removal (Islam et al., 2010) such as zeolite (Sehperi et al., 2014), kaolinite (Tribe et al., 2012) and iron-modified pumice (Golestanifar et al., 2015). Pumice is one of natural pozzolan created by release of gases during cooling and solidification of lava. Pumice has low weight, porous structure and a large surface area. The utilization of pumice mainly is for structural applications such as aggregate in light weight concrete, cements, and filters. However, nowadays, pumice also has been used as adsorbent for pollutant removal from water and wastewater (Shayesteh et al., 2016, Indah et al., 2017). So far the studies of nitrate removal from water were mostly performed by using modification of pumice (Golestanifar et al., 2015) and only few studies used the natural pumice (Kim et al., 2015).

However, in spite of the capability of adsorbents to remove pollutant in the water, the used adsorbent may raise a problem to environment because they have to be discarded after it becomes exhausted. Moreover, the use of mineral like natural pumice as adsorbent may reduce the availability of natural resources. Hence, the regeneration and reuse of the adsorbents are necessary to make the operation environmental friendly and minimize the requirement of adsorbent. For this, desorption and reuse of the adsorbents in adsorption-desorption cycles could help in reducing the residues. However, so far, there is only limited investigations on the 
adsorption and desorption as well as regeneration of natural pumice to remove pollutant in water or wastewater.

At Sungai Pasak, West Sumatra, Indonesia, pumice is available in a great abundance, as byproduct of the process of sand mining in that area. In this study, the capability of that local mineral to remove nitrate from aqueous solution under different experimental conditions was examined. Batch experiment and isotherm studies were conducted on a laboratory scale to determine the adsorption capacity of natural pumice. The parameters affecting the adsorption process such as $\mathrm{pH}$ of solution, dose of adsorbent, contact time, diameter of adsorbent and initial concentration on removal of nitrate were studied. Furthermore, to study regeneration ability of the natural pumice, sequential adsorption-desorption cycles were conducted three times using the same adsorbent. The results of this study could provide more information about the capability of the natural pumice, mainly from local natural resources and also to solve the problem of high nitrate concentration that may become a serious common water quality problem in agricultural regions, like in Indonesia.

\section{Methods}

\subsection{Preparation of adsorbent}

Pumice samples were collected from riverside of Sungai Pasak, West Sumatera, Indonesia as byproduct of the process of sand mining in that area. Pumice samples were washed with distilled water several times and dried out at room temperature, then crushed and sieved in order to produce the desired particle size fractions. A scanning electron microscopy (SEM, model S$3400 N$, Hitachi, Japan) was used to observe the surface morphology of pumice and energy dispersive X-ray (EDX) spectroscopy was also employed to obtain information on the oxide content of the natural pumice.

\subsection{Batch adsorption experiments}

Batch adsorption experiment were performed at room temperature $\left(20-25^{\circ} \mathrm{C}\right)$ by varying $\mathrm{pH}(4-8)$, dose of adsorbent $(0.3-30 \mathrm{mg} / \mathrm{L})$, contact time (15$75 \mathrm{~min})$, diameter of adsorbent $(\varangle 63-600 \mu \mathrm{m})$ and initial concentration of nitrate ( $15-90 \mathrm{mg} / \mathrm{L})$. In each experiment, $100 \mathrm{ml}$ of nitrate solutions was contacted with pumice and gently agitated at 100 $\mathrm{rpm}$. After a period of time, the mixture was filtered by using Whatman's filter paper no 42 and the concentration of nitrate in the filtrate was determined by a UV-vis spectrophotometer (Shimadzu UV-2600). The amount of nitrate adsorbed by the natural pumice was obtained as the difference between the initial and final concentration of the solutions. All experiments were repeated three times, and results presented are consequently the averaged values of replicate tests. The removal efficiency and the nitrate uptake $\left(q_{e}, \mathrm{mg} / \mathrm{g}\right)$ on natural pumice was calculated by the following mass-balance equation:

$$
\begin{aligned}
& \text { Removal (\%) }=\frac{C_{0}-C_{e}}{C_{0}} \times 100 \% \\
& q_{e}=\frac{C_{0}-C_{e}}{m} \times V
\end{aligned}
$$

where $C_{0}$ is the initial concentration of nitrate ( $\mathrm{mg} / \mathrm{L}), C_{\mathrm{e}}$ is the equilibrium concentration of nitrate $\mathrm{g}(\mathrm{mg} / \mathrm{L}), V$ is the volume of the solution $(\mathrm{L})$, and $m$ is the mass of the pumice $(\mathrm{g})$.

\subsection{Batch desorption experiment}

The desorption experiment was carried our using pumice with total chromium adsorbed on the surface at the end of the adsorption experiment. Samples were mixed with $0.1 \mathrm{M} \mathrm{HCl}$ (a 1:200 solid to solution ratio), shaken at $100 \mathrm{rpm}$ for $60 \mathrm{~min}$ and at room temperature $(250 C)$. Subsequently, the mixture was filtered by using Whatman's filter paper no 42 and the concentration of nitrate ions in the filtrate was determined a UV-vis spectrophotometer (Shimadzu UV-2600). All experiments were repeated three times, and results presented are consequently the averaged values of replicate tests. The desorbed total chromium was calculated as percentage using equation (Eq. (3))

$$
\text { Percent of desorption }=\frac{\text { Concentration of metal desorbed }}{\text { Concentration of metal adsorbed }} \times 100 \%
$$

\section{Results and Discussion}

\subsection{Pore structure and elemental composition of natural pumice}

Fig. 1 shows the SEM image showed the surface morphology of natural pumice from Sungai Pasak, West Sumatra, Indonesia.

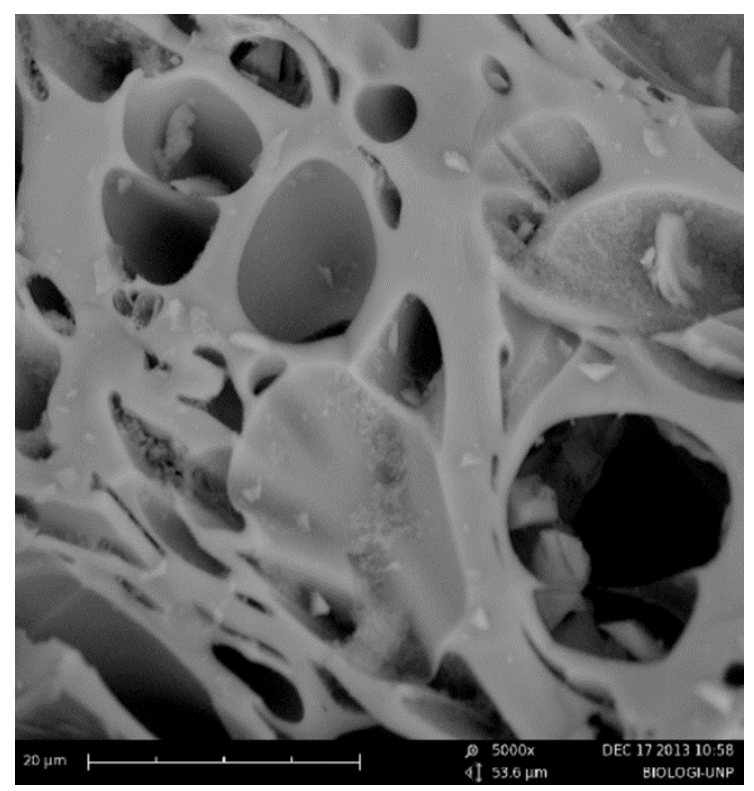

Fig. 1. SEM micrograph of pumice from Sungai Pasak, West Sumatra, Indonesia. 
The image indicated that the pumice had a highly porous, smooth surface, cellular and irregular texture with larger cavities, which provides suitable sites for adsorption. As shown in Table 1, Si, Al and Fe are the major elements in natural pumice from Sungai Pasak, as determined by EDX. Other elements, except K, Ca, $\mathrm{Na}$ and $\mathrm{Mg}$ were present in relatively smaller amounts (less than $3 \%$. from Sungai Pasak. In table 1, the elemental compositions of pumice fro Lombok, West Nusa Tenggara is also presented to compare with pumice. There are some differences in the weight percentage of the element in the both pumice. It shows the different locations of pumice have different elemental compositions that may affect the adsorption capabilities of the pumices. The elemental compositions of the pumice also indicate the absence of hazardous or carcinogenic substances, thus the pumice are considered appropriate as adsorbent to treat polluted water.

Table 1. Elemental and oxide composition of natural pumice from Sungai Pasak, West Sumatra and Lombok, West Nusa Tenggara, Indonesia

\begin{tabular}{ccc}
\hline \multirow{2}{*}{ Element } & \multicolumn{2}{c}{ \% weight } \\
\cline { 2 - 3 } & $\begin{array}{c}\text { Sungai Pasak, } \\
\text { Indonesia }\end{array}$ & $\begin{array}{c}\text { Lombok, } \\
\text { Indonesia }\end{array}$ \\
\hline $\mathrm{O}$ & 56.38 & 43.34 \\
$\mathrm{Na}$ & 0.49 & 4.54 \\
$\mathrm{Mg}$ & 0.06 & - \\
$\mathrm{Al}$ & 3.89 & 9.81 \\
$\mathrm{Si}$ & 32.56 & 34.94 \\
$\mathrm{~K}$ & 2.41 & 3.21 \\
$\mathrm{Ca}$ & 1.2 & 1.23 \\
$\mathrm{Fe}$ & 3 & 2.92 \\
\hline
\end{tabular}

\subsection{Effect of pH}

Adsorption of nitrate by natural pumice was investigated in the $\mathrm{pH}$ range 4-8. Fig. 2 shows that the adsorption of nitrate on natural pumice is strongly $\mathrm{pH}$ dependent. The removal efficiency and nitrate uptake decreased with increasing $\mathrm{pH}$ and the most effective $\mathrm{pH}$ value for nitrate removal was 4 , the lowest $\mathrm{pH}$ of the variation of $\mathrm{pH}$ studied. The reason for this might be due to at the lower $\mathrm{pH}$, the amount of $\mathrm{H}^{+}$ions in the solution are more than $\mathrm{OH}^{-}$ ions. It caused the reduction of the negative charge on the surface due to the excess of protons in the solution and as a result, the number of positively charged sites increase. A positively charged surface site on the adsorbent favors the adsorption of the nitrate anions due to electrostatic attraction.

A sharp decline in removal efficiency of nitrate occurred at higher $\mathrm{pH}$ that may be due to electrostatic repulsion of anionic nitrate by the negatively charged adsorbents surface. The decrease in sorption capacity at the higher $\mathrm{pH}(\mathrm{pH}>$ 4) can be due to the competition for the active sites by $\mathrm{OH}^{-}$ions and the electrostatic repulsion of anionic nitrate by the negatively charged surface of natural pumice. In addition, the $\mathrm{pHpzc}(\mathrm{pH}$ point of zero charge) values of pumice are in the range of 67 , as reported in the literature (Karimaian et al., 2013; Sepehr et al., 2013). When $\mathrm{pH}<\mathrm{pHzpc}$, the surface of the sorbent has got more positive charge which causes the electrostatic attraction between positively charged surface ions and nitrate ions (Sepehr et al., 2013). Since generally, pH values of soil and groundwater are ranging from 5 to 9 , the natural pumice could be used as adsorbent for removal of nitrate effectively (Golestanifar et al., 2015). Similar finding on $\mathrm{pH}$ trend has been reported in adsorption of nitrate studies by other researchers (Öztürk and Bektas, 2004; Golestanifar et al., 2015). Thus, above all the following experiments were carried out with $\mathrm{pH}$ values of 4 .

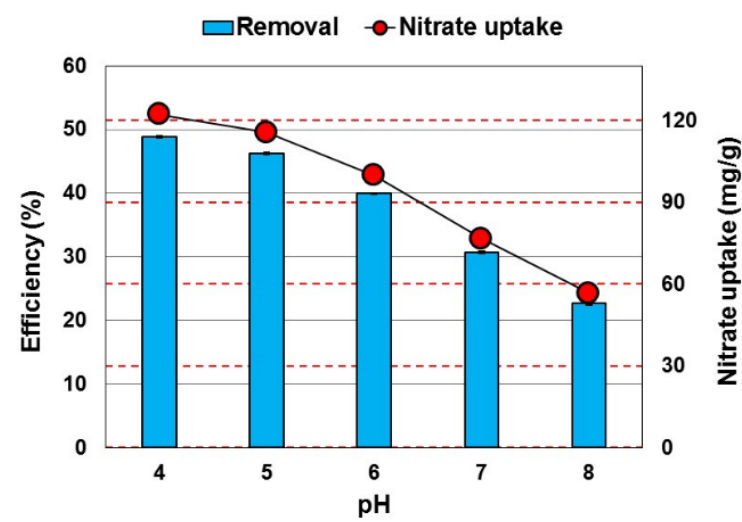

Fig. 2. Effect of $\mathrm{pH}$ on nitrate uptake onto natural pumice ( nitrate concentration $=75 \mathrm{mg} / \mathrm{L}$; adsorbent dose $=0.3 \mathrm{~g} / \mathrm{L}$; diameter of adsorbent $=<63 \mu \mathrm{m}$; contact time $=60 \mathrm{~min}$ ). Data represent averages of triplicates \pm SE.

\subsection{Effect of Adsorbent Dose}

Fig. 3 shows the removal efficiency and nitrate uptake as a function of adsorbent dosage. The nitrate removal efficiency increases from 47.90 to $77.52 \%$ as the adsorbent dose increases from 0.3 to $30 \mathrm{mg} / \mathrm{L}$ which is due to the increase in the available active sites and larger surface area of the adsorbents. However, on the contrary, decreasing of nitrate uptake gradually was observed from 119.75 to $1.94 \mathrm{mg} / \mathrm{g}$ as the adsorbent dose increases from $0.01 \mathrm{~g}$ to $0.1 \mathrm{~g}$. The results revealed that the higher adsorbent dose will result in a lower nitrate uptake indicating the heterogeneous of adsorbent surface sites. According to the surface site heterogeneity model, the surface is composed of sites with a spectrum of binding energies. At a low adsorbent dose, all types of sites are entirely exposed and the adsorption on the surface is saturated faster, showing a higher adsorption capacity whereas at a higher adsorbent dose the availability of higher energy sites decreases with a larger fraction of lower energy sites occupied, resulting in a lower adsorption capacity. In addition, as the adsorbent dose increased, the agglomeration of adsorbent 
particles may occur that reducing the available external surface area and an increase in diffusional path length both of which contribute to decrease in amount adsorbed per unit mass. Similar results are documented in the literatures reported by the other investigators (Dash et al., 2015; Shayesteh et al., 2016; Indah et al., 2017). The highest nitrate uptake at equilibrium of $119.75 \mathrm{mg} / \mathrm{g}$ was observed for a natural pumice dose of $0.3 \mathrm{~g} / \mathrm{L}$. Thus, $0.3 \mathrm{~g} / \mathrm{L}$ of adsorbent dose was determined to be the optimum dose in this study and above all the following experiments were carried out with this dose.

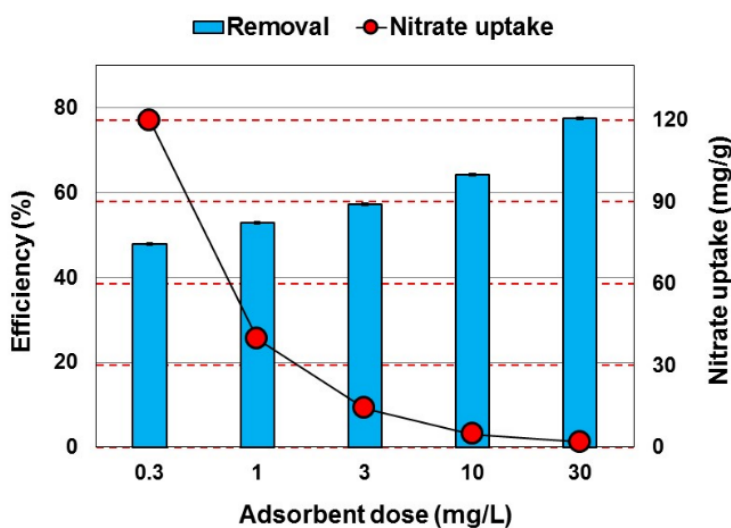

Fig. 3. Effect of adsorbent dose on nitrate uptake onto natural pumice (nitrate concentration $=75 \mathrm{mg} / \mathrm{L}$; diameter of adsorbent $=<63 \mu \mathrm{m} ; \mathrm{pH}=4$; contact time $=60 \mathrm{~min}$ ). Data represent averages of triplicates \pm SE.

\subsection{Effect of Contact Time}

Contact time is an important parameter to determine the equilibrium time of adsorption process. The sorption of nitrate on natural pumice was investigated as a function of contact time (15$75 \mathrm{~min}$ ) and the effect of the time on the removal efficiency and nitrate uptake is shown in Fig. 4. As it is shown, by increasing contact time from 15 to 30 min, the removal efficiency and nitrate uptake increased and reached to the highest values, 57.21\% ant $143.03 \mathrm{mg} / \mathrm{g}$, respectively.

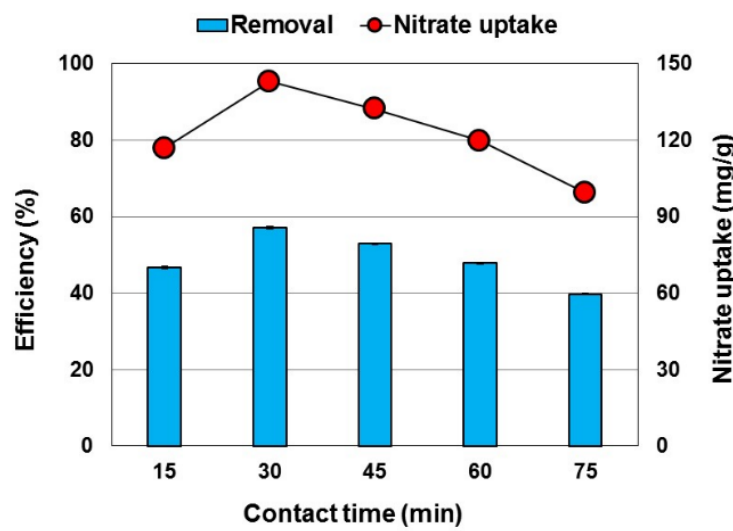

Fig. 4. Effect of contact time on nitrate uptake onto natural pumice (nitrate concentration $=75 \mathrm{mg} / \mathrm{L}$; diameter of adsorbent $=<63 \mu \mathrm{m} ; \mathrm{pH}=4$; adsorbent dose $=0.3 \mathrm{~g} / \mathrm{L}$ ). Data represent averages of triplicates \pm SE.

Nevertheless, at increasing time to 90,120 and 150 min, the decreasing of removal efficiency and nitrate uptake was observed. The result denoted that the adsorption of nitrate is most rapid in the initial stages and gradually decreases until the equilibrium is reached. It was attributed to the fact that during the initial stage of adsorption, a large number of vacant surface sites of pumice was available for adsorption resulted the increasing removal efficiency and nitrate uptake. After an interval in time, due to repulsive forces between the solute molecules on the adsorbent surface and the bulk phase, the remaining vacant surface sites of pumice were occupied (Golestanifar et al., 2015; Shayesteh et al., 2016). Therefore, the equilibrium time for the removal of nitrate from aqueous solution by natural pumice is found to be $30 \mathrm{~min}$ and applied for further experiments.

\subsection{Effect of Diameter of Adsorbent}

Fig. 5 shows the effect of particle sizes of natural pumice on the adsorption of nitrate. For this, five variations of diameter representing the variation of particle size of adsorbent were applied. The removal efficiencies decreased from 57.07 to $29.19 \%$ and nitrate uptakes decreased from 142.68 to $72.97 \mathrm{mg}$ $\mathrm{lg}$ as diameter of adsorbent increase from $\varangle 63$ to 500-600 $\mu \mathrm{m}$ The results indicated that the removal efficiency and nitrate uptake depend on the size of adsorbent; as the diameter of adsorbent decreases, the removal efficiency and nitrate uptake increase. It may due to the wider exchange surface area provided at the adsorbent that have fine particles for the adsorption of the nitrate ions. Similar results were also reported in the literature using other adsorbents (Lopez-Nuñez et al., 2014; Zhang et al., 2015). Thus, $\varangle 63 \mu \mathrm{m}$ was determined as the optimum diameter of adsorption and were applied for the further experiments.

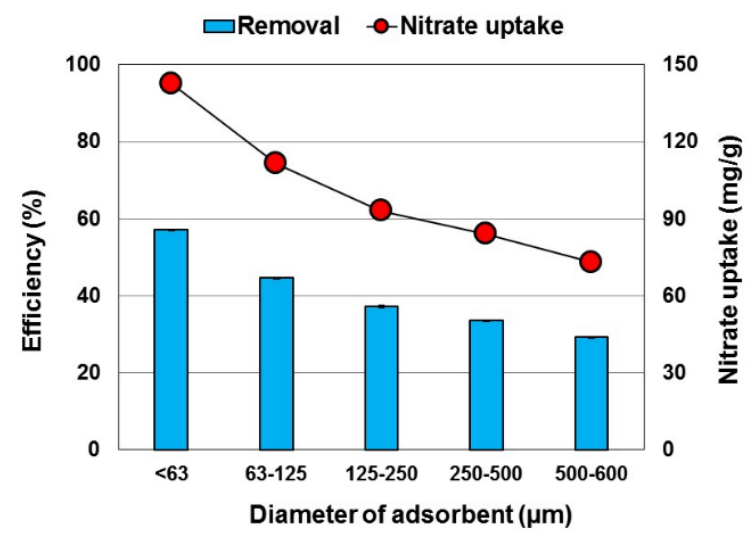

Fig. 5. Effect of diameter of absorbent on nitrate uptake onto natural pumice (nitrate concentration $=75 \mathrm{mg} / \mathrm{L} ; \mathrm{pH}$ $=4$; adsorbent dose $=0.3 \mathrm{~g} / \mathrm{L}$; contact time $=30 \mathrm{~min}$ ). Data represent averages of triplicates $\pm \mathrm{SE}$.

\subsection{Effect of initial concentration}

The influence of initial nitrate concentration on adsorption was presented in Fig. 6. The initial concentration of nitrate solution was varied from 15 to $75 \mathrm{mg} / \mathrm{L}$. Results revealed that the removal efficiencies and nitrate uptakes increased from 36.70 to $54.79 \%$ and 18.35 to $164.37 \mathrm{mg} / \mathrm{g}$, respectively, as the initial nitrate concentration increased from 15 to $90 \mathrm{mg} / \mathrm{L}$. This behavior is due to higher availability of nitrate ions in the higher 
concentration of solution, which provides a stronger driving force to overcome mass transfer resistance of nitrate ions between the aqueous and solid phases. This phenomenon generate higher probability of collision between nitrate ions and active sites of natural pumice that leading to a higher nitrate uptake. The results demonstrate that the adsorption of nitrate onto natural pumice is dependent on initial metal concentration and is consistent with the finding by other investigators (Golestanifar et al., 2015).

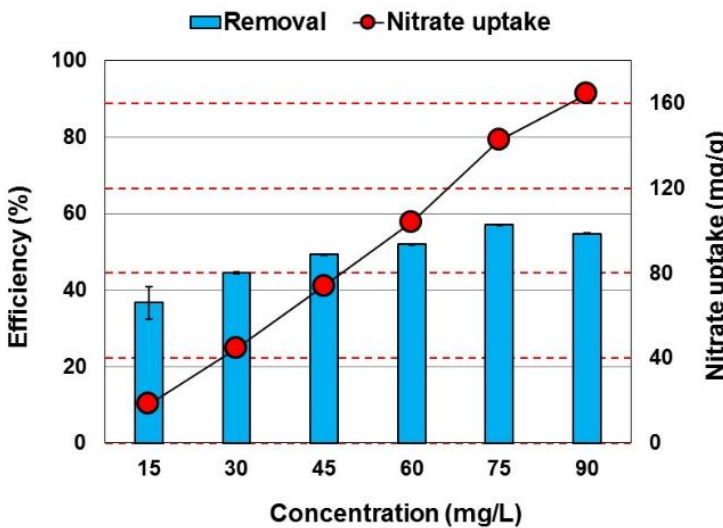

Fig. 6. Effect of initial concentration on nitrate uptake onto natural pumice $(\mathrm{pH}=4$; adsorbent dose $=0.3 \mathrm{~g} / \mathrm{L}$; contact time $=30 \mathrm{~min}$; diameter of adsorbent $=<63 \mu \mathrm{m})$. Data represent averages of triplicates \pm SE.

\subsection{Adsorption Isotherm Models}

In order to describe how solutes interact with adsorbents and how the molecules are distributed between the liquid and the solid phases at equilibrium during the adsorption process, an adsorption isotherm is important to study. Moreover, the adsorption isotherm also could give information on the maximum capacity of the adsorbent or the amount needed to remove a unit mass of pollutant under the system conditions. A number of isotherm models have been developed to describe equilibrium relationships and identifying the best-fit isotherm is critical for optimizing the adsorption process design. Linear forms of the Freundlich, Langmuir and Elovich adsorption isotherm models ((4), (5) and (6), respectively) are as follows:

$$
\begin{gathered}
\log q_{e}=\log K_{F}+\frac{1}{n} \log C_{e}(4) \\
\frac{C_{e}}{q_{e}}=\frac{C_{e}}{q_{\max }}+\frac{1}{K_{L} \times q_{\max }}(5) \\
\ln \frac{q_{e}}{C_{e}}=\ln K_{E} q_{\max }-\frac{q_{e}}{q_{\max }}(6)
\end{gathered}
$$

where $C e$ is the equilibrium concentration, $q e$ is the amount of adsorbate adsorbed per unit mass of adsorbent, qmax is the maximum adsorption capacity, $K_{F}$ is the Freundlich isotherm constant related to adsorption capacity (indicating the quantity of nitrate adsorbed onto the adsorbent), $n$ is the Freundlich isotherm constant related to adsorption intensity (indicating the favorability of the adsorption process), $K_{L}$ is the Langmuir constant related to the adsorption rate and $K_{E}$ is the Elovich equilibrium constant.
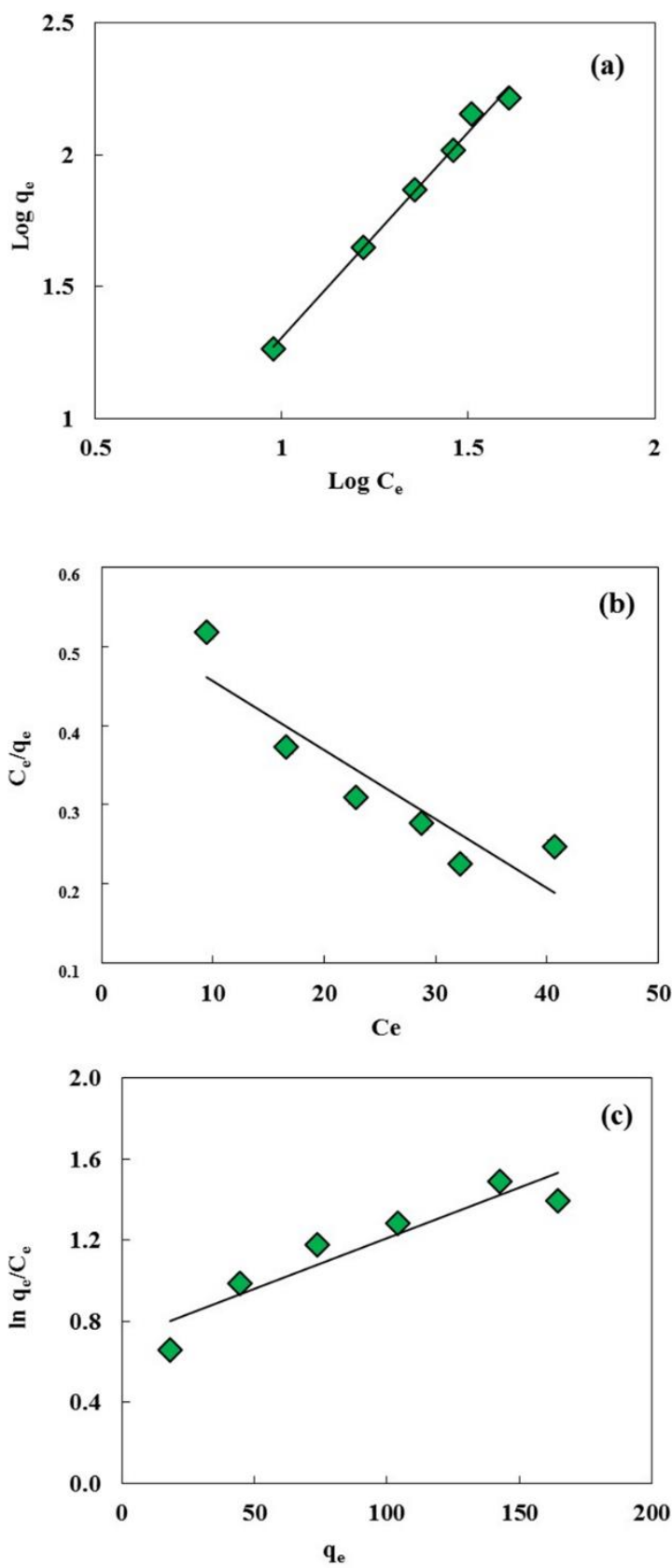

Fig. 7. Freundlich (a), Langmuir (b) and Elovich (c) isotherm plots for the adsorption of nitrate onto natural pumice (nitrate concentration $=15-90 \mathrm{mg} / \mathrm{L}$; adsorbent dose $=0.3 \mathrm{~g} / \mathrm{L}$; contact time $=30 \mathrm{~min} ; \mathrm{pH}=3$ ).

The Freundlich model assumes that reactions take place in several sorption sites and as the amount of solute adsorbed rises, the binding surface energy decreases exponentially which means multilayer sorption. The linear form of the Freundlich isotherm model yields a straight line. The slope and intercept of the obtained fit are used to calculate the Freundlich constants $1 / n$ and $K_{F}$ (Freundlich, 1906). The Langmuir isotherm is based on the assumptions that adsorption takes place at specific homogeneous sites within the adsorbent, there is no significant interaction among adsorbed 
species, and the adsorbent is saturated after the formation of one layer of adsorbate on the surface of adsorbent. From the slopes and the intercepts, a linear fit to the Langmuir equation yields Langmuir constant $\left(K_{L}\right)$ and the maximum adsorption capacity $\left(q_{\max }\right)$, respectively (Langmuir, 1916). The Elovich model is based on a kinetic principle assuming that the adsorption sites increase exponentially with adsorption, which implies a multilayer adsorption. The Elovich maximum adsorption capacity and Elovich constant can be calculated from the slopes and the intercepts of the plot of In ( $q e / C e)$ versus qe (Elovich and Larinov, 1962). The applicability of the isotherm equations to describe the adsorption process was judged based on the maximum value of adsorption and correlation coefficients $\left(R^{2}\right)$, which are a measure of goodness of fit.

The adsorption isotherm of nitrate adsorption onto natural pumice was determined by varying the initial nitrate concentration in the interval ranging from 15 to $90 \mathrm{mg} / \mathrm{L}$ with 3 of $\mathrm{pH}$ and $0.3 \mathrm{~g} / \mathrm{L}$ of adsorbent dose. Fig. 7 shows the Langmuir, Freundlich and Elovich isotherm plots and Table 2 presents the isotherm model constants for the adsorption. From Table 2, it was revealed that compared to Langmuir and Elovich isotherm models, the Freundlich isotherm model offers the highest $R 2$ value (0.992) indicated the model fitted well with the equilibrium data. The result described that the adsorption of nitrate onto natural pumice is multilayer sorption, which the adsorption occurred on the heterogeneous surface of pumice and the active sites of pumice have different energy, as the Freundlich isotherm model's assumption (Freundlich, 1906).

Table 2. Isotherm model constants for adsorption of nitrate onto natural pumice

\begin{tabular}{cccc}
\hline Isotherm & \multicolumn{2}{c}{ Constants } & $\mathrm{R}^{2}$ \\
\hline \multirow{2}{*}{ Freundlich } & $1 / n$ & $K_{F}(\mathrm{~L} / \mathrm{g})$ & 0.992 \\
& 1.561 & 0.556 & \\
\hline \multirow{2}{*}{ Langmuir } & $q_{\max }(\mathrm{mg} / \mathrm{g})$ & $K_{L}(\mathrm{~L} / \mathrm{mg})$ & 0.823 \\
& -114.943 & -0.01 & \\
\hline \multirow{3}{*}{ Elovich } & $q_{\max }(\mathrm{mg} / \mathrm{g})$ & $K_{E}(\mathrm{~L} / \mathrm{mg})$ & 0.874 \\
& -200.0 & 0.996 & \\
\hline
\end{tabular}

It is shown in Table 2, the value of the Langmuir isotherm constants are negative, indicated the inadequacy of this model for explaining the adsorption process (Öztürk and Bektas, 2004). From the Freundlich isotherm model, the adsorption of nitrate onto natural pumice from Sungai Pasak resulted $0.556 \mathrm{mg} / \mathrm{g}$ of $\mathrm{KF}$ as adsorption capacity and 1.561 of $1 / n$. The $1 / n$ value describes the linearity of adsorption and typically the values range from 1 downwards. When $1 / n<1$, it corresponds a normal L-type Langmuir adsorption isotherm, while $1 / n>1$ reflects a co-operative adsorption (Kumar and Jiang, 2015). Smaller value of $1 / n$ implies an effective interaction between the adsorbent and adsorbate. How ever, the value of $1 / n$ from this study was obtained 1.561 and it reflected that co-operative adsorption may occur in the system. Co-operative adsorption is the adsorption where adsorbed adsorbate has an effect on the adsorption of "new" adsorbate molecules. Furthermore, $1 / n$ values of $>1$ are also indicative of S-type isotherms, according to the Giles et al. (1960) classification. The $\mathrm{S}$ curve of the adsorption isotherm generally reflects strong competition between the solvent and the adsorbed species for the adsorbent surface sites. The S-type characterized first by a weak adsorption which then gradually increases suggesting a weak surface interaction and competitive adsorbate-adsorbate interactions. In order to generate a stronger interaction between natural pumice as adsorbent and nitrate solution as adsorbate for this study, more attempts could be made, such as modify the surface of the adsorbent physically or chemically using thermal treatment, protonation or metal oxides impregnation (Sepehr et al, 2014).

\subsection{Desorption study}

To investigate the regeneration and recycling of spent adsorbents, batch desorption experiments were conducted. For this, the adsorptiondesorption experiments in three consecutive cycles by using $0.1 \mathrm{M} \mathrm{HCl}$ as desorbing agent were carried out. The efficient removal of loaded nitrate from the natural pumice was necessary to ensure its long term use for repeated adsorption-desorption cycles. The regeneration of the adsorbent is likely to be a key factor in accessing the potential of the adsorbent for commercial application.

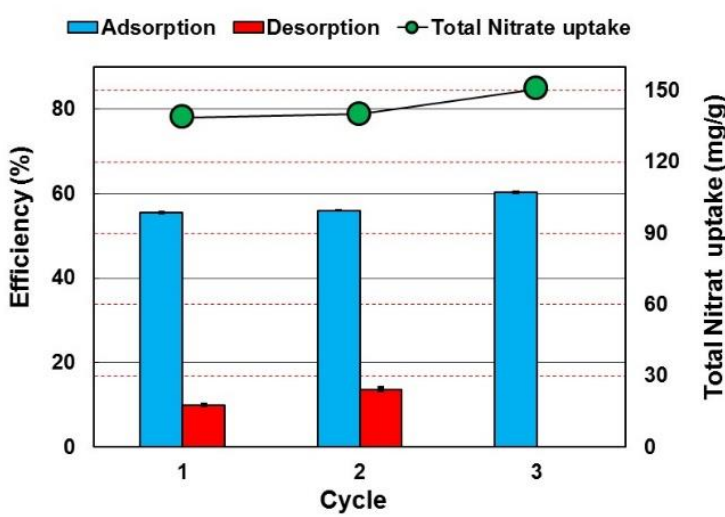

Fig. 8. Adsorption and desorption efficiencies as well as nitrate uptake onto pumice at 3 cycles of adsorptiondesorption $(\mathrm{pH}=3$; adsorbent dose $=0.3 \mathrm{~g} / \mathrm{L}$; contact time $=30 \mathrm{~min}$; diameter of adsorbent $=<63 \mu \mathrm{m}$; nitrate concentration $=75 \mathrm{mg} / \mathrm{L}$ ). Data represent averages of triplicates \pm SE.

As shown in Fig. 8, the desorption efficiencies for nitrate ions by using $0.1 \mathrm{M} \mathrm{HCl}$ as desorbing agent were in the range of $10-13 \%$ Desorption efficiency slightly increased approximately $3 \%$ at the second desorption cycle (desorption 2). It may due to the accumulation of nitrate ions that could not release until the second adsorption (adsorption 2). 
Although complete desorption were not achieved, the result confirmed that $\mathrm{HCl}$ can be used as desorbing and recovery agent. In desorption process, the residence time is very essential because the higher the residence time, the longer the contact between the desorbing agent and the loaded adsorbent, so that the desorption efficiency may increase. Desorption efficiency of $\mathrm{Cr}(\mathrm{VI})$ ion from natural pumice obtained from Tikmeh Dash Reign, East Azerbaijan, Iran reached 94.3\%after 300 min contact time with $1 \mathrm{M} \mathrm{HCl}$ (Sepehr et al., 2014). In this study, the desorption time was $30 \mathrm{~min}$. If the contact time is extended, it may be possible to reach $100 \%$ desorption.

\section{Conclusions}

To solve high nitrate concentration problem in water that may occur at the agricultural regions, natural pumice as local mineral from Sungai Pasak, West Sumatra, Indonesia, was investigated to become an alternative low-cost adsorbent for nitrate removal from water. This pumice is available in a great abundance, as by-product of the process of sand mining in that area. From the batch experiments, it was revealed that the adsorption of nitrate onto natural pumice was dependent on $\mathrm{pH}$, adsorbent dose, contact time, diameter of adsorbent and initial nitrate concentration. The optimum condition of nitrate removal by natural pumice were 3 of $\mathrm{pH}$ solution, $0.3 \mathrm{~g} / \mathrm{L}$ of adsorbent dose, 30 min of contact time of adsorption, $<63 \mu \mathrm{m}$ of particle size, and $90 \mathrm{mg} / \mathrm{L}$ of nitrate concentration with $164.37 \mathrm{mg} / \mathrm{g}$ of nitrate uptake onto pumice. The experimental data were fitted well to Freundlich's adsorption equilibrium isotherm within the concentration range studied as it presents higher $R^{2}$ value than that of the Langmuir and Elovich isotherms. It reflected that the adsorption of nitrate onto natural pumice is multilayer sorption and the active sites of pumice have different energy. From the desorption experiment, it was confirmed that, although complete desorption were not achieved, the result confirmed that $\mathrm{HCl}$ can be used as desorbing and recovery agent, which be desorbed $10-13 \%$ of nitrateion. Thus, the used natural pumice also could be regenerated and reused up to three successive adsorption-desorption cycles. From the overall results, it can be remarked that easy availability of natural pumice as local mineral in West Sumatra, Indonesia and its ability to adsorb and retain nitrate will create more interest to develop new natural adsorption method of pollutant removal from solution.

\section{Acknowledgement}

The authors are thankful to Faculty of Engineering, Universitas Andal as, Indonesia (Grand No. 046/UN16.09.D/PL/2017) for supporting this work.

\section{References}

Baes, B.U., Jung, Y.H., Han, W.W., Shin, H.S., 2002. Improved Brine Recycling during Nitrate Removal Using lon Exchange. Water Research 36: 3330-3340. doi: 10.1016/S0043-1354(02)00012-X

Bhatnagar, A., Sillanpa, M., 2011. A review of emerging adsorbents for nitrate removal from water. Chemical Engineering Journal 168: 493-504. doi: 10.1016/j.cej.2011.01.103

Dash, S.S., Sahu, M.K., Sahu, Patel, E.R.K., 2015. Fluoride removal from aqueous solutions using cerium loaded mesoporous zirconium phosphate. New Journal of Chemistry 39: 7300-7308. doi: 10.1039/C5NJ01030F

Elovich S.Y., Larionov, O.G., 1962. Theory of adsorption from solutions of non electrolytites on solid adsorbents. Russian Chemical Bulletin 11: 191-197. doi: 10.1007/BF00908016

Freundlich, H., 1906. Uber die adsorption in losungen. Zeitschrift für Physikalische Chemie 57: 385-470.

Giles, C.H., MacEwan, T.H., Nakhwa, S.N., Smith, D., 1960. A System of Classification of Solution Adorption Isotherms and Its Use in Diagnosis of Adsorption Mechanisms and in Measurement of Specific Surface Areas of Solids. Journal of the Chemical Society 0: 3973-3993. doi: 10.1039/JR9600003973

Golestanifar, H., Asadi, A., Alinezhad, A., Haybati, B., Vosoughi, M., 2015. Isotherm and kinetic studies on the adsorption of nitrate onto nanoalumina and iron-modified pumice. Desalination and Water Treatment 57:5480-5487. doi:10.1080/19443994.2014.1003975

$\mathrm{Hu}$, H.Y., Goto, N., Fujie, K., 2001. Effect of pH on the Reduction of Nitrite in Water by Metallic Iron. Water Research 35: 2789-2793. doi: 10.1016/S00431354(00)00570-4

Indah, S., Helard, D., Edwin, T., Pratiwi, R., 2017. Utilization of pumice from Sungai Pasak, West Sumatra, Indonesia as low-cost adsorbent in removal of manganese from aqueous solution. AIP Conference Proceedings 1823: 020072. doi: 10.1063/1.4978145

Islam, M., Mishra, P.C., Patel, R., 2010. Physicochemical characterization of hydroxyapatite and its application towards removal of nitrate from water. Journal of Environmental Management 91: 18831891. doi: 0.1016/j.jenvman.2010.04.013

Karimaian, K.A., Amrane, A., Kazemian, H., Panahi, R., Zarrabi, M., 2013. Retention of phosphorous ions on natural and engineered waste pumice: Characterization, equilibrium, competing ions, regeneration, kinetic, equilibrium and thermodynamic study. Applied Surface Science 284: 419-431. doi: 10.1016/j.apsusc.2013.07.114

Kumar, A.S.K., Jiang, S.J., 2015. Preparation and characterization of exfoliated graphene oxide-Lcystine as an effective adsorbent of $\mathrm{Hg}$ (II) adsorption. RSC Advance 5: 6294-6304. doi: 10.1039/C4RA12564A

Langmuir, I., 1916. The constitution and fundamental properties of solids and liquids. Part I. Solids. The Journal of the American Chemical Society 38: 22212295. doi: 10.1021/ja02268a002

Liao, C.H., Kang, S.F., Hsu, Y.W., 2003. Zero-valent iron reduction of nitrate in the presence of ultraviolet light, organic matter and hydrogen peroxide. Water Research 37: 4109-4118. doi: 10.1016/S00431354(03)00248-3

Liao, X.P., Shi, B., 2005. Adsorption of Fluoride on Zirconium(IV)-Impregnated Collagen Fiber. Environmental Science and Technology 39: 46284632. doi: 10.1021/es0479944 
Lopez-Nuñez, P.V., Aranda-García, E., Cristiani-Urbina, M.C., Morales-Barrera, L., Cristiani-Urbina, E., 2014. Removal of hexavalent and total chromium from aqueous solutions by plum ( $P$. domestica $L$.) tree bark. Environmental Engineering and Management Journal 13: 1927-1938.

Oztürk, N., Bektas, T.E., 2004. Nitrate removal from aqueous solution by adsorption onto various materials. Journal of Hazardous Materials 112: 155162. doi: 10.1016/j.jhazmat.2004.05.001

Pinter, A., Batista, J., 2006. Improvement of an Integrated Ion-Exchange/Catalytic Process for Nitrate Removal by Introducing a Two-Stage Denitrification Step. Applied Catalysis B: Environmental 63: 150-159. doi: 10.1016/j.apcatb.2005.10.006

Schipper, L.A., Vukovic, M.V., 2001. Five Years of Nitrate Removal, Denitrification and Carbon Dynamics in a Denitrification Wall. Water Research 35: 3473-3477. doi: 10.1016/S0043-1354(01)00052-5

Shayesteh, H., A. Rahbar-Kelishami, and R. Norouzbeigi 2016. "Evaluation of natural and cationic surfactant modified pumice for congo red removal in batch mode: Kinetic, equilibrium, and thermodynamic studies". Journal of Molecular Liquids 221: 1-11. doi: 10.1016/j.molliq.2016.05.053

Sepehr, M.N., Sivasankar, V., Zarrabi, M., Kumar, M.S. 2013. Surface modification of pumice enhancing its fluoride adsorption capacity: An insight into kinetic and thermodynamic studies. Chemical Engineering Journal 228: 192-204. doi: 10.1016/j.cej.2013.04.089

Sepehr, M.N., Amrane, A.B., Karimaian, K.A., Zarrabi, M., Ghaffari, H.R., 2014. Potential of waste pumice and surface modified pumice for hexavalent chromium removal: Characterization, equilibrium, thermodynamic and kinetic study. Journal of the Taiwan Institute of Chemical Engineers 45: 635-647. doi: 10.1016/j.jtice.2013.07.005

Tribe, L., Hinrichs, R., Kubicki, J. D., 2012. Adsorption of Nitrate on Kaolinite Surfaces: A Theoretical Study. Journal of Physic Chemistry B, 116 (36), 126611273.

Ward, M.H., deKok, T.M., Levallois, P., Brender, J., Gulis, G., B.T. Nolan, J. Van Derslice. 2005. "Workgroup report: Drinking-water nitrate and health-recent findings and research needs". Environmental Health Perspective 113: 1607-1614. doi: 10.1289/ehp.8043

Zhang X, L. Guo, Y. Wang, C. Ruan. 2015. "Removal of oxygen demand and nitrogen using different particle-sizes of anthracite coated with nine kinds of LDHs for wastewater treatment". Scientific Reports 5: 15146. doi: 10.1038/srep15146 